\title{
O PROCESSO COGNITIVO-DISCURSIVO DE CONSTRUÇÃO DE SENTIDO EM NOTÍCIAS E PIADAS: UMA ABORDAGEM BASEADA EM FRAMES
}

\author{
THE COGNITIVE-DISCURSIVE PROCESS OF MEANING CONSTRUCTION \\ IN NEWS AND JOKES: A FRAME-BASED APPROACH
}

\author{
Ewerton William Estevam de Souza \\ Paulo Henrique Duque $e^{\mathrm{ii}}$
}

\begin{abstract}
RESUMO: O trabalho tem o objetivo de identificar os principais frames ativados em textos que versam sobre terrorismo, preconceito, crise econômica e política e humor. Trata-se de temas que tornam nítidos os movimentos discursivos de construção de conceitos e comportamentos sociais e políticos. A metodologia tem como ponto de partida a identificação de frames: estruturas conceptuais acionadas no discurso. A partir disso, serão realizados grafos: esquemas cuja função é representar um grupo de conceitos inseridos em uma rede de proposições. Os grafos objetivam representar o acionamento desses frames para a construção de sentido, conforme a Semântica de frames. Ao fim do trabalho, pretende-se apresentar um procedimento de escrutínio do framing subjacente ao discurso, a partir das pistas linguísticas apresentadas no texto, buscandose compreender com mais acurácia o papel desempenhado pelo léxico para perspectivar frames relacionados aos temas.
\end{abstract}

PALAVRAS-CHAVE: Frame. Grafo. Construção de sentido.

ABSTRACT: The identification of the main frames activated in texts that refer to terrorism, prejudice, economic and political crisis and humor is the purpose of this research. These themes are responsible to evidence the discursive movements of construction of concepts and social and political behaviors. The methodology started with the identification of frames: conceptual structures activated in the discourse. Then, graphs were applied: schemas with the main purpose of representing a group of concepts inserted in a network of propositions. According to the semantics of frames, the graphs used in this study aim to represent the activation of these frames in order to construct meaning. At last, the presentation of a procedure of scrutiny of framing underlying the discourse was intended using linguistic hints presented in the text. Also, a more accurate comprehension of the role played by the lexicon was intended in order to visualize frames related to the themes.

KEYWORDS: Frame. Graph. Construction of meaning.

\footnotetext{
Graduando em Letras na Universidade Federal do Rio Grande do Norte. E-mail: ewerton10@yahoo.com.br.

ii Doutor em Linguística pela Universidade Federal do Rio de Janeiro. Atualmente é professor associado da Universidade Federal do Rio Grande do Norte e coordenador do Grupo de Pesquisa Cognição \& Práticas Discursivas (C\&PD). E-mail: duqueph@gmail.com.
} 


\section{Introdução}

Diferentemente do que se acreditava nos estudos linguísticos tradicionais, a linguagem por si mesma não carrega significado, ou seja, ela e o enquadramento ${ }^{1}$ contextual em si não comportam sentido, no entanto, servem como poderosas ferramentas que incitam construções online ${ }^{2}$ de significado, as quais vão muito além de formas gramaticais e lexicais. Nesse sentido, a linguagem é compreendida como um guia de sentido, uma vez que grande parte do conteúdo inferencial que extraímos de uma sentença não está contida nela (FAUCONNIER, 2014).

Nesse cenário, operações complexas mentais dentro de uma rede de domínios são ativadas para a construção do sentido. Elas incluem o conhecimento cognitivo de fundo da cena, modelos conceptuais assim como espaços mentais. A Linguística Cognitiva tem buscado respostas aos intricados esquemas por trás da gramática, isto é, à riqueza de sistemas conceituais subjacentes e à complexidade de configurações esquemáticas no discurso. Nessa perspectiva, a linguagem visível é somente a ponta do iceberg do significado invisível (FAUCONNIER, 1997; DUQUE; COSTA, 2011).

Dessa forma, são diversos os mecanismos cognitivos acionados pelas construções gramaticais, que, nessa ótica, acionam um conteúdo lexical em uma intricada rede de frames conectados, os quais, por sua vez, estão conectados e ancorados em outros recursos cognitivos como metáfora, metonímia, inferência, espaços mentais, mesclagem, recursividade, categorias de nível básico, fenômeno prototípico e esquemas imagéticos (FAUCONNIER; TURNER, 1994; LAKOFF, 1990).

Partindo-se dessa abordagem, esta pesquisa, oriunda de iniciação científica, faz parte do projeto de pesquisa científica Discurso, framing e metáforas sistêmicas, da Universidade Federal do Rio Grande do Norte. Escolheu-se focar seu objetivo na identificação dos frames, um dentre tantos outros mecanismos necessários à construção de sentido; o que não implica dizer

\footnotetext{
${ }^{1}$ Framing.

2 Por online se entende que o significado é construído no momento da leitura. Por essa expressão, pretendemos nos afastar do modo tradicional dos estudos linguísticos que concebem que o significado das palavras já é pré-concebido na mente do leitor.
} 
que outros desses recursos cognitivos não serão evocados durante a pesquisa, uma vez que, como já foi dito e será exposto mais adiante, todas essas ferramentas cognitivas estão conectadas e entrincheiradas, sendo impossível estudá-las isoladamente.

Portanto, este trabalho objetiva analisar especificamente notícias/reportagens sobre terrorismo, preconceito, política e crise econômica, disponíveis em jornais e revistas online ${ }^{3}$, e de piadas, recolhidas de um blog. A escolha desses domínios conceptuais se deveu ao fato de eles se relacionarem a visões de mundo antagônicas entre si, o que torna nítidos os movimentos discursivos de construção de conceitos e comportamentos sociais e políticos. 0 posicionamento sobre o que é o humor e o que pode ou não causar o riso, por exemplo, vem sendo tema de intenso debate. Por serem antagônicas e bem marcadas as visões do humor, as diferenças das narrativas de cotidiano subjacentes se tornam mais salientes e, portanto, mais fáceis de se capturar.

A partir da análise, serão identificados os principais frames e, posteriormente, serão elaborados gráficos de estruturas reticuladas dos mesmos (grafos), os quais têm o objetivo de representar os principais frames ativados no discurso, postulado que, dentro da Linguística Cognitiva, eles são um dos aparatos cognitivos usados para a compreensão do texto (FILLMORE, 1975). Os grafos servirão como instrumentos que nos proporcionarão entender melhor como os frames são evocados e relacionados para influenciar nossas visões de mundo e até que ponto são responsáveis por comportamentos políticos e sociais.

Vale ressaltar que, não obstante o foco da análise seja os frames, outros aparatos do pensamento empregados para compreensão da linguagem, tal qual a metáfora e o espaço mental, serão discutidos mais especificamente nas seções a seguir.

\section{Semântica de frames}

Segundo Fillmore (1982), frames são estruturas cognitivas armazenadas em nosso cérebro adquiridas a partir de nossas experiências, da nossa cultura

\footnotetext{
${ }^{3}$ Neste trecho e na seção Metodologia, o termo "online" é usado no sentido tradicional (disponível na internet).
} 
e da forma com a qual nos relacionamos com o mundo. Ao serem armazenados na memória de longo prazo, os frames tornam-se responsáveis pelo reconhecimento e pela detecção de padrões, o que implica dizer que eles são essenciais para a estruturação dos conceitos, das relações e dos objetos do mundo.

Palavras (pistas linguísticas) funcionam como indexadores de sentido, isto é, ativam frames. Entretanto, como explicitado por Fillmore (1976), essa ativação não depende necessariamente da linguagem, mas sim em como essa linguagem é aplicada. Dessa forma, uma mesma estrutura linguística pode ativar frames distintos, isso porque o que vai direcionar o acionamento de frames é a perspectiva adotada pelo autor do texto.

Além disso, uma palavra focaliza somente uma parte do frame, de modo que nenhuma palavra fornece a estrutura completa dele (CROFT; CRUSE, 2004). Por exemplo, no trecho abaixo "por que a Polônia é imune ao terrorismo, enquanto o resto da Europa sofre?" 4 é ativado o frame SOFRER. Partindo do pressuposto de que frames são eventos complexos que envolvem participantes, estados e mudanças de estado (BERTOLDI; CHISHMAN 2013), o trecho destacado fornece somente algumas partes do frame: a vítima do sofrimento (Europa), a causa do sofrimento (ataque terrorista), mas não fornece, por exemplo, o causador do sofrimento (grupos radicais) ou a motivação (o fato de a Europa ter caçado o estado islâmico na Síria). Duque (2015) classifica esse perfilamento dos papéis do frame pelo contexto situacional como unificação.

Na linguística cognitiva, o conceito de frame se popularizou na Semântica de Frames, uma teoria que tem o objetivo de descrever sistematicamente o significado de uma língua. Fillmore é o nome mais proeminente no que se refere a essa descrição. O autor, ao longo de seus trabalhos, tem proposto uma teoria semântica baseada na Semântica da compreensão ${ }^{5}$ (FILLMORE, 1977, 1982, 1985; PETRUCK, 1996).

\footnotetext{
4 Disponível em: http://www.gazetadopovo.com.br/ideias/por-que-a-polonia-e-imune-aoterrorismo-enquanto-o-resto-da-europa-sofre-adlf7if92y2nh9lmus1kkszll. Acesso em: 10 maio 2018.

${ }^{5}$ Semantic of understanding (U-semantic).
} 
Tal perspectiva vai de encontro à Semântica de condições de verdades ${ }^{6}$, a qual tem o objetivo de caracterizar as condições necessárias e suficientes sobre as quais sentenças individuais de uma dada língua podem ser verdadeiras. Nesse sentido, o autor argumenta que esse objetivo é secundário para a interpretação do sentido. Em contraste, Fillmore considera os frames como ferramentas úteis na semântica lexical, textual e gramatical, ancorados na relação entre texto, contexto e experiência.

A Semântica de frames configura-se como um modelo de análise que visa a uma representação da organização e da representação dos conceitos (frames) na nossa mente. Portanto, ela tem o objetivo de explicar as variações de sentidos de itens lexicais. Metodologicamente, essas representações são feitas por meio de grafos, os quais objetivam descrever o acionamento dos frames ativados por itens lexicais. Eles são mapas cognitivos que visam à representação de um grupo de conceitos inseridos em uma rede de proposições. É uma forma de estruturar visualmente significados, conceitos e relações (MOREIRA; SALOMÃO, 2012).

Cabe esclarecer que o grafo é uma tentativa de representação dos conceitos em nossa mente. Uma vez que os frames são conectados, ativados e acionados em diferentes níveis, representá-los graficamente tal qual acontece na cognição é impossível. Por exemplo, em notícias com as quais nos deparamos cotidianamente, é comum o frame MUÇULMANO estar conectado a ATAQUE TERRORISTA. Ao ler uma dessas palavras, por meio da inferência, frames relacionados, ISLAMISMO, HOMEM-BOMBA, por exemplo, ficam em stand-by (no fundo da cena, em outro nível cognitivo), ou seja, ficam ativados, prontos para serem acionados, podendo vir à tona, ou não, dependendo do foco do frame construído pelo texto. Grosso modo e de modo sucinto, é como se tais frames estivessem "à espera" de serem evocados. Esse mecanismo é chamado de evocação, segundo Duque (2015).

Segundo Croft e Cruise (2004), a construção dos frames é baseada na nossa experiência (conhecimento de mundo). Ao ler um texto, relacionamos e ligamos conceitos a todo o momento. Nesse sentido, um frame só pode ser

\footnotetext{
${ }^{6}$ Semantic of truth (T-semantic).
} 
descrito juntamente com outros frames, uma vez que a compreensão de um conceito não é obtida isoladamente, mas a partir de sua posição em um sistema de conceitos, ou seja, a compreensão de um texto se faz a partir do acionamento de vários frames relacionados por ligações semânticas.

Portanto, para entender e interpretar um conceito, é necessário compreender toda a estrutura de conceitos que o engloba. (JONHSON, 1987; MOREIRA; SALOMÃO, 2012). Dessa forma, a depender da escolha lexical e da construção do texto, diferentes conceitos (frames) podem ser erigidos à medida que outros sentidos ficam apagados. Esse movimento configura-se como uma estratégia utilizada pelo produtor do texto para induzir a um sentido pretendido, movimento que é mais perceptível em textos argumentativos.

\section{Metáfora}

A noção de Mente Corporificada e a Teoria Neural da Metáfora (LAKOFF; JOHNSON; 1980; JOHNSON, 1987; LAKOFF, 1987) preconizam que o nosso sistema conceitual é corporificado, ou seja, nossa compreensão do mundo se dá por meio da estrutura corporal e da relação desta com o ambiente. 0 pensamento, nessa perspectiva, é construído por meio de metáforas e de esquemas imagéticos (esquemas-I), que são estruturas organizacionais corporificadas, as quais são formadas a partir das nossas experiências mais básicas com o mundo.

Duque (2015) classifica os esquemas-I como um tipo de frame, sendo que a diferença entre ambos é o fato de os frames serem adquiridos por intermédio das experiências mais abstratas, por isso exigindo um processamento cognitivo mais abstrato e, portanto, menos corporificado. Tais frames são construídos necessariamente pela interação social, cujo papel da cultura é fundamental, como por exemplo, frames como TERRORISMO e PRECONCEITO.

Já os esquemas imagéticos são construídos pela interação do corpo com o ambiente, de modo que o sistema sensório-motor é fundamental. Dito com outras palavras, as experiências mais concretas e, por isso, de um processamento cognitivo em nível perceptual, são a base para esses esquemas, 
os quais, por serem os primeiros esquemas cognitivos a se formarem, são a base para o pensamento mais abstrato, por meio da metáfora.

Dessa forma, a mente é metafórica por natureza e grande parte da nossa linguagem é estruturada por metáforas (GIBBS, 2007). As projeções metafóricas sofrem o processo conhecido como Princípio da Invariância, responsável por fazer o mapeamento entre o domínio fonte (mais concreto) e o domínio alvo (mais abstrato), de modo que o mapeamento preserva a estrutura do domínio fonte na estrutura do domínio alvo (LAKOFF, 1993).

Nesse sentido, as palavras são responsáveis por ativar esquemas. Por exemplo, construções espaciais como "em", "sobre", "de" e "para" ativam os esquemas CONTÊINER ${ }^{7}$ e TRAJETÓRIA, analisados exaustivamente a partir de Lakoff (1980). Apesar de cada língua ser organizada de forma diferente, ou seja, possuir sua própria rede de estrutura linguística (princípios e regras que regem seu funcionamento), os esquemas usados para configurá-la em todas as línguas são os mesmos, sendo organizados apenas de maneira diferente (FELDMAN, 2006).

No trecho “... o país também atingiu pela primeira vez a meta estabelecida para as nações da chamada zona do euro..." ${ }^{8}$, o domínio fonte TRAJETÓRIA, ou seja, uma trajetória espacial, estrutura o domínio fonte OBJETIVO, isto é, atingir um objetivo é percorrer uma trajetória. Com isso, pode-se observar a estreita relação entre esses dois domínios, de modo que os componentes espaciais de TRAJETÓRIA (domínio fonte) estruturam os componentes de OBJETIVO (domínio alvo), sendo, dessarte, impossível se pensar na construção analisada sem recorrer à metáfora.

Considerando-se a capacidade de esquemas imagéticos originarem e estruturarem construções abstratas, Grady (1997) classifica as metáforas que têm como domínio fonte esses esquemas (isto é, aqueles que envolvem algum tipo de conteúdo ligado à percepção física ou sensorial, tal qual o exemplo analisado anteriormente, que envolve a percepção de distância) como metáforas primárias.

\footnotetext{
${ }^{7}$ Neste trabalho, os frames e esquemas estão destacados em MAIÚSCULA e os papéis dos esquemas em itálico.

${ }^{8}$ Disponível em: <http://www.bbc.com/portuguese/internacional-39501022>. Acesso em: 08 maio 2018.
} 
Já as metáforas complexas são derivadas das primárias, entretanto elas são perpassadas pelos valores culturais, como pode ser observado no exemplo "o bom desempenho da economia coloca o país na posição de um "oásis" em meio à turbulência política que atinge a Europa“"9 (o grafo desse texto está na Figura 3, na seção Análise).

Portanto, concebendo-se a ideia de que a metáfora mapeia a combinação de dois frames distintos (palavras literais, por si mesmas) em um terceiro frame (palavra metafórica, no contexto), e, constatada sua importância para pensamento e linguagem, a projeção metafórica torna-se indissociável ao modelo de representação de frames em foco neste trabalho (LANGACKER, 2008; SULLIVAN, 2007; BOUVERET; SWEESTER, 2009).

\section{Espaços mentais}

Segundo Fauconnier (1994 [1985]), espaços mentais são blocos cognitivos estruturados por frames e modelos cognitivos construídos online ao lermos e compreendermos narrativas para fins de compreensão específica naquele momento. Tais espaços são configurados e ligados sob a pressão da gramática, do contexto e da cultura. Isso cria uma série de espaços à medida que o discurso se desdobra e possibilita a continuidade ao longo dele.

Portanto, tais espaços mentais são construídos, interconectados e mesclados na memória pela ativação do conhecimento subjacente dos frames, que se desdobram em enquadres lexicais, isto é, perspectivas adotadas pelo texto, ao passo que o discurso se desenvolve, e podem ser modificados dinamicamente com 0 desdobramento do pensamento e do discurso (FAUCONNIER; TURNER, 2003; FERRARI, 2008).

Dessa maneira, estruturas em determinados espaços incorporam frames e conceitualizações esquemáticas, com isso os elementos do espaço, responsáveis por focalizar alguns aspectos do frame, de forma dinâmica no instante do pensamento (FAUCONNIER; TURNER, 1998), encaixam-se em

\footnotetext{
${ }_{9}^{9}$ Disponível em: http://www.bbc.com/portuguese/internacional-39501022. Acesso em: 10 maio 2018.
} 
modelos cognitivos advindos do conhecimento de fundo e elaborados contextualmente durante um discurso particular (SMITH, 2004).

Como já discutido, o discurso nunca revela todas as relações e componentes do frame, então, por exemplo, ao lermos o trecho "ataques terroristas motivaram medidas de segurança da Câmara de Lisboa"10, o espaço mental em que Lisboa instala medidas de segurança, construído no momento da leitura, tem elementos individuais que fazem parte do frame maior INIMIGO, AMEAÇA, em que Lisboa desempenha o papel de ameaçado.

Os espaços são conectados tanto aos frames armazenados na memória de longo prazo, (por exemplo, o frame TRAJETÓRIA), quanto a especificações contextuais desse frame (por exemplo, a trajetória de Duque ao Monte Evereste). Esses espaços podem ser ativados de diferentes maneiras. Por exemplo, se eu digo que "eu acho que a sociedade é preconceituosa", o espaço configura um evento do pensamento (FAUCONNIER; TURNER, 2002).

Os espaços, outrossim, são importantes para compreendermos o contrafactual, como hipóteses ("eu acho"), representações (filmes, pinturas, fotografias, histórias), tempo ("em 1960") (MOK; BRYANT; FELDMAN, 2004). Dessa maneira, há o espaço inicial (base), geralmente o da realidade, que, gera um "filho", o espaço (M), e o estrutura de várias formas.

Explicando com mais clareza, ao ler a sentença anterior, há a criação de dois espaços mentais: um espaço base $B$, configurando a estrutura correspondente até o ponto em que introduzo o pensamento, e um espaço $M$, subordinado a este, que contém a estrutura correspondendo ao que eu penso. A expressão "eu acho" é chamada de construtor de espaço, uma vez que é a base para o segundo espaço.

\section{Ligação entre os frames}

Em relação à ligação entre os frames, segundo Duque (2015), há quatro tipos de mecanismos possíveis: constituência, subcategorização, evocação e unificação.

\footnotetext{
${ }^{10}$ Disponível em: https://www.dn.pt/portugal/interior/ataques-terroristas-motivaram-mOrg.idasde-seguranca-da-camara-de-lisboa---mai-8717456.html. Acesso em: 10 maio 2018.
} 
a. Por meio da constituência, frames complexos, isto é, que envolvem mais de um frame e diferentes relações, "são estruturados por frames ainda mais simples, até chegar a frames espaciais mais básicos (esquemas-I)" (DUQUE, 2015, p. 40). Considere o exemplo já discutido "o país também atingiu pela primeira vez a meta estabelecida para as nações da chamada zona do euro". Pelo menos dois frames mais simples (esquemas imagéticos) constituem o frame complexo: TRAJETÓRIA (o percurso realizado pelo trajetor) e TRAJETOR-MARCO (Trajetor = REFERENTE = PAÍS; marco = ZONA DO EURO).

Esse mecanismo é essencial para a compreensão da conexão entre os nós (nodes), ou nódulos, pois, uma vez que se sabe que a estrutura dos grafos possui frames e partes de eventos, e que esses elementos não estão isolados, mas sim conectados em uma rede estrutural de sentido, de modo que os frames estão dispostos em nós, a constituência manifesta-se na conexão entre os frames. Portanto, para a análise do corpus, foi adotado que a conexão entre frames se dá por meio dos papéis e relações dos esquemas imagéticos.

A partir da análise realizada, foram encontradas as seguintes relações e papéis dos frames: é; tem; parte de; dentro de; fora de; agente e meta. Uma descrição mais detalhada pode ser vista na Tabela 1.

Tabela 1 - Papéis e relações dos esquemas utilizados nos grafos

\begin{tabular}{|c|c|}
\hline Esquemas imagéticos & Papéis e relações \\
\hline LIGAÇÃO PARTE-TODO: & $\begin{array}{l}\text { "é" é uma atribuição de traços e "tem" significa que um } \\
\text { frame tem determinados traços/características. } \\
\text { "parte de": Significa que um frame é parte de um todo. }\end{array}$ \\
\hline $\begin{array}{l}\text { CONTÊINER } \text { e } \text { LIGAÇÃO } \\
\text { CONTEÚDO-CONTINENTE: }\end{array}$ & $\begin{array}{l}\text { "dentro de": significa que um frame está no interior de um } \\
\text { CONTÊINER. } \\
\text { "fora de": significa que um frame está no exterior de um } \\
\text { CONTÊINER. }\end{array}$ \\
\hline $\begin{array}{l}\text { TRAJETÓRIA e LIGAÇÃO EI } \\
\text { OS PONTOS DA TRAJETÓF }\end{array}$ & $\begin{array}{l}\text { "agente" (trajetor): refere-se a um trajetor que percorre uma } \\
\text { trajetória para atingir uma "meta" (objetivo pretendido). }\end{array}$ \\
\hline
\end{tabular}

Fonte: Dados da pesquisa, com base em Duque (2015).

Vale salientar que não há uma metodologia definida para a análise estrutural dos frames, visto que o trabalho de Fillmore não se ateve à análise 
empírica para a elaboração dessas redes articuladas. Logo, é possível encontrar diversos trabalhos que adotaram perspectivas diferentes no que concerne à estrutura dos grafos (TEIXEIRA, 2014; MIRANDA; LOURES, 2016; BERTOLDI; CHISHMAN 2013; ARAÚJO, 2017).

No entanto, neste trabalho, optou-se por considerar que os esquemas imagéticos configuram-se como a base para a organização dos frames, de modo que foi criada uma sistematização metodológica para a análise dos frames visando sua representação ontológica, que estabelece que somente os esquemas-I são os responsáveis por conectar os nós.

b. A subcategorização atua no nível da ligação hierárquica entre os frames. No exemplo "caminhões são incendiados e governo fala em atentado" ${ }^{11}$, CAMINHÃO é um tipo de VEÍCULO, que é um tipo de MEIO DE TRANSPORTE, que, por fim, é um CONTÊINER. Dessa forma, os papéis dos frames subordinados herdam os papéis do frame maior CONTÊINER (portal $=$ porta do caminhão, limites $=$ extremidades do caminhão, exterior $=$ floresta [fornecido pelo contexto] e interior $=$ dentro do caminhão).

c. A evocação acontece quando frames invocam instâncias de outros frames sem que haja constituência ou subcategorização. Existem diversas estruturas e papéis envoltos num frame, no entanto, evocamos somente aqueles mais relevantes à construção do sentido, enquanto as outras estruturas e papéis menos relevantes ficam disponíveis (no fundo) para serem evocadas quando necessário.

d. Por fim, o mecanismo de unificação permite que os papéis de um frame sejam preenchidos por elementos do discurso anterior ou pelo contexto situacional

\footnotetext{
${ }^{11}$ Disponível em: https://veja.abril.com.br/mundo/chile-29-caminhoes-sao-incendiados-e-
} governo-fala-em-atentado/. Acesso em: 31 abril 2018. 


\section{Metodologia}

A metodologia consistiu na análise de um corpus constituído de 31 textos disponíveis em sites. As notícias e reportagens foram retiradas de jornais online, enquanto as piadas, do site https://www.tediado.com.br/08/12-piadas-para-rir-ecompartilhar ${ }^{12}$. Foram selecionadas as primeiras notícias e reportagens encontradas, não havendo, portanto, critérios de seleção, a não ser o do eixo temático. O corpus é divido em dois eixos: notícias/reportagens (sobre preconceito, terrorismo, crise política e econômica) e piadas curtas, as quais foram selecionadas sem nenhum critério, conforme a Tabela 2.

Tabela 2 - Desenho do corpus ${ }^{13}$

\begin{tabular}{|l|l|l|l|l|}
\hline $\begin{array}{l}\text { Gênero } \\
\text { textual: }\end{array}$ & \multicolumn{2}{|l|}{ Notícia e reportagem } & Piada \\
\hline Tipo textual: & \multicolumn{2}{|l|}{ Predominantemente narrativo, descritivo e expositivo } & $\begin{array}{l}\text { Predominantemente } \\
\text { Narrativo e dialogal }\end{array}$ \\
\hline Tema: & Preconceito & Terrorismo & Crise econômica e política & Variado \\
\hline Quantidade: & 4 & 5 & 11 & 11 \\
\hline
\end{tabular}

Fonte: Dados da pesquisa.

A metodologia de análise desses textos tem como ponto de partida a identificação dos frames, por meio da análise de discursos envolvendo participantes diferentes. Acredita-se que, dessa forma, seja possível estabelecer se tais discursos se fundamentam em frames compartilhados na base de padrões recorrentes. Podem-se identificar frames, conforme o projeto já citado, por meio de:

a. Pressuposição, ou seja, o emissor de uma mensagem tomar por garantia que o leitor ou ouvinte tem acesso a determinada informação.

b. Modo de pensar, uma vez que pessoas muito frequentemente argumentam tomando por base os frames que elaboram suas visões de

\footnotetext{
12 Acesso em: 05 maio 2018.

${ }^{13}$ Os conceitos dos gênero e da tipologia textual descritos nesta tabela baseiam-se em Marcuschi (2002).
} 
mundo. O framing como perspectivação estratégica pode também estar envolvido no raciocínio por propósitos persuasivos.

c. Estrutura reticulada de palavras pertencentes a um mesmo domínio conceptual que ativam e modelam o mesmo frame. Se um trecho de discurso contém muitos itens linguísticos que pertencem ao mesmo domínio conceptual, e então ativam o mesmo frame, então isso pode indicar que este pedaço de discurso de certo modo envolve este frame.

d. Projeções e mapeamentos metafóricos para embasar suas metáforas conceptuais, conforme já discutido anteriormente.

A partir da leitura dos textos, foram identificadas as palavras-chave, isto é, aquelas responsáveis por fornecer uma maior carga semântica à ideia central do texto. Dessa forma, essas palavras, pertencentes ao mesmo domínio lexical e responsáveis por evocar os principais conceitos envolvidos, foram tomadas como base vistas à identificação dos frames e à elaboração dos grafos, dispostos na seção Análise.

\section{Análise}

$\mathrm{Na}$ análise, atentou-se para os principais frames ativados, ou seja, aqueles mais essenciais ao entendimento do texto. Dito com outras palavras, frames menos relevantes não foram incluídos. Por exemplo, na Figura 1, o fato de o frame RENAULT evocar MARCA não foi considerado na estrutura do grafo porque se pressupõe que o leitor já saiba dessa informação. Além disso, tal informação é um caso de subcategorização, sendo um frame específico de RENAULT, por isso menos relevante para a compreensão global do texto.

Malgrado o número grande de análises, somente serão descritos cinco exemplos, pois não se pretende esgotar o tema, mas somente oferecer uma noção geral de como a metodologia proposta é aplicada à identificação de frames e uma base para futuras análises envolvendo a construção de grafos. 
Escolhemos 1 texto sobre preconceito, 1 sobre terrorismo, 1 sobre crise econômica e política e 2 textos de humor para explorarmos na análise. Pequenos trechos de cada texto serão transcritos para a melhor compreensão do grafo. Embora analisado o texto por completo, consideramos que os trechos mostrados a seguir concentram as informações centrais do texto.

O grafo do primeiro exemplo analisado, na Figura 1, foi elaborado conforme os seguintes trechos: "Renault é acusada de preconceito contra nordestinos em comercial", "Renault chamou nordestinos de 'preguiçosos' em novo comercial e foi criticada na web; marca retirou vídeo do ar", "Renault afirmou que a intenção da campanha era 'quebrar preconceitos'”14.

Figura 1 - Representação em grafo do texto 1

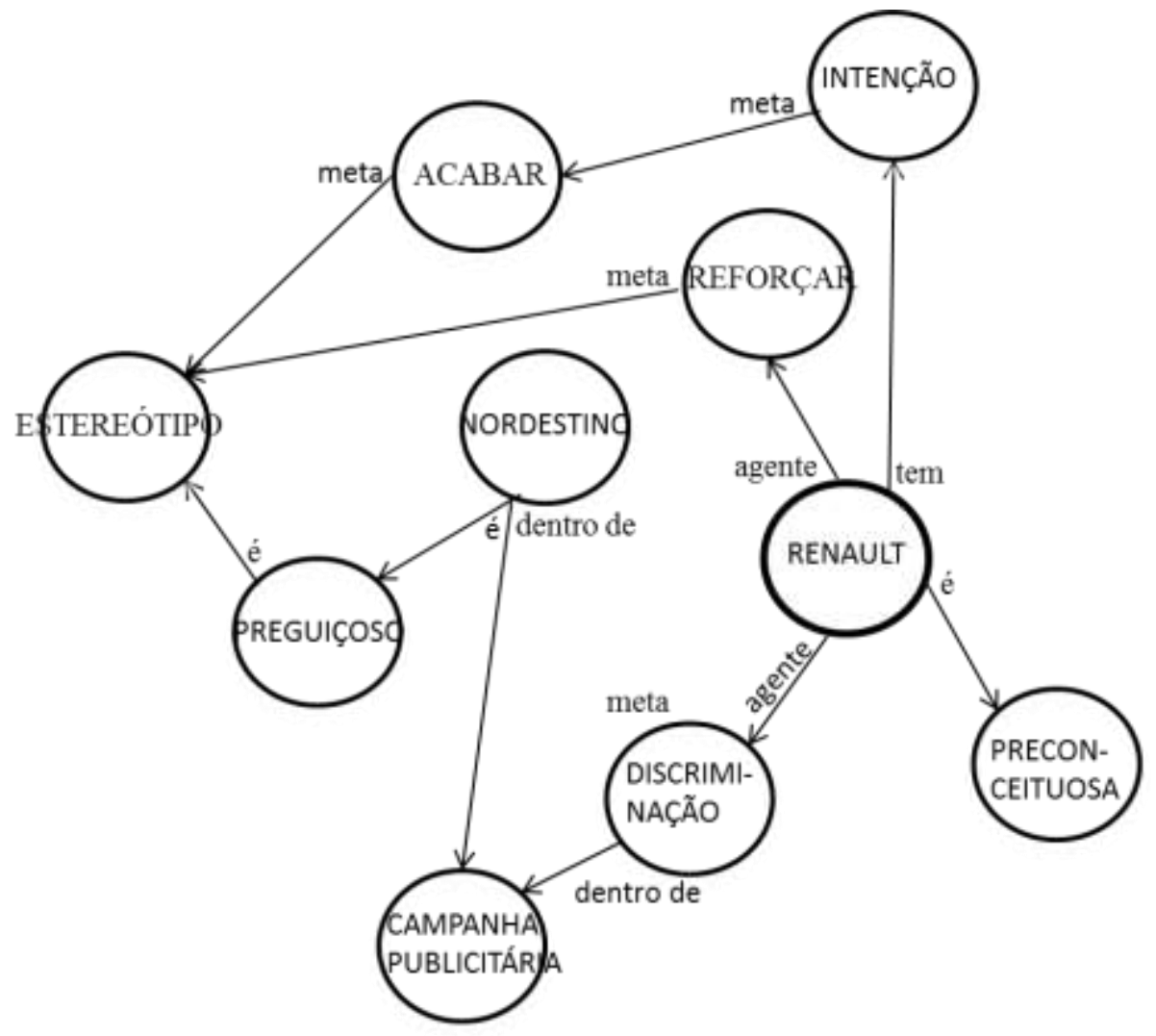

Fonte: Dados da pesquisa.

\footnotetext{
${ }^{14}$ Disponível em: http://jconline.ne10.uol.com.br/canal/mundo/brasil/noticia/2017/08/30/renaulte-acusada-de-preconceito-contra-nordestinos-em-comercial-304385.php. Acesso em: 31 abril 2018.
} 
Como descrito na metodologia, os frames dentro dos nós são os conceitos evocados pelo texto, enquanto as relações entre eles são baseadas nos esquemas-I descritos na Tabela 1.

RENAULT agente DISCRIMINAÇÃO meta NORDESTINO significa que o trajetor RENAULT tem como meta a DISCRIMINAÇÃO, a qual por sua vez tem como meta o NORDESTINO. NORDESTINO é PREGUIÇOSO, PREGUIÇOSO é ESTEREÓTIPO e RENAULT é PRECONCEITUOSA são atribuições de traços. NORDESTINO e DISCRIMINAÇÃO dentro de CAMPANHA PUBLICITÁRIA significa que ambos os conceitos estão (metaforicamente) no interior da CAMPANHA.

INTENÇÃO meta ACABAR meta ESTEREÓTIPO significa que a meta da RENAULT (objetivo pretendido) era ACABAR com o ESTEREÓTIPO. Vale salientar que a meta é metafórica, uma vez que não se trata de uma meta espacial. Acabar com o estereótipo, entretanto, está dentro do espaço mental da INTENÇÃO, uma vez que está no pensamento da RENAULT, objetivo que não foi alcançado, segundo o texto, já que o que a marca conseguiu na verdade foi reforçar o estereótipo.

Desse modo, podemos observar que o texto claramente aciona uma visão de mundo que denigre a campanha publicitária e a imagem da marca por reforçar o preconceito de que o nordestino é preguiçoso. Lakoff (2004), no seu livro Don't Think of an Elephant!: Know Your Values and Frame the Debate, já discorria a respeito da capacidade do frame ser evocado mesmo sendo negado. O exemplo clássico adotado pelo autor é a situação hipotética na qual alguém recebe a ordem de não pensar em um elefante; o que culmina na pessoa pensando no animal, ou seja, mesmo que o frame seja negado, ele é ativado.

Portanto, o autor sugere que, para que haja o reforço da ideia que queremos incutir, devemos enquadrar nossos próprios valores, visões e sentidos e evitar atacar o que queremos combater. Esse foi o caso da campanha em questão, que, numa tentativa de combater o preconceito contra nordestinos, acabou ressaltando-o.

Cumpre esclarecer que os grafos são construídos com base na perspectiva do texto, portanto, ele representa o espaço mental do texto, o que não necessariamente corresponde à realidade. Portanto, em exemplos como 
RENAUL é PRECONCEITUOSA ou MAPUCHE RADICAL é AMEAÇA (grafo posterior), tais julgamentos de valores não provêm da interpretação a priori do autor do texto, mas única e exclusivamente dos indexadores linguísticos e pistas inferenciais fornecidos pelo próprio texto.

\section{Figura 2 - Representação em grafo do texto 2}

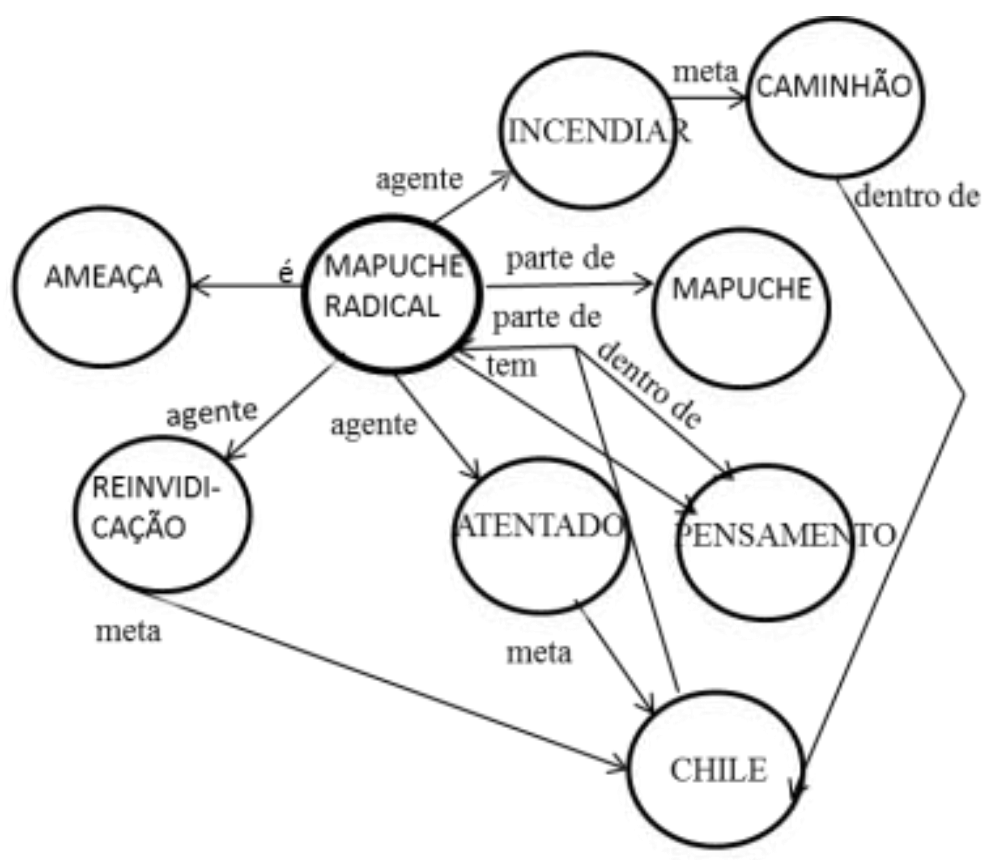

Fonte: Dados da pesquisa.

Sobre o tema do terrorismo, extraiu-se o seguinte trecho do texto para a elaboração do grafo: "Chile: 29 caminhões são incendiados e governo fala em atentado", "Com frequência, o sul do Chile é palco de ataques incendiários. Alguns já foram reivindicados por grupos mapuches radicais, que exigem a restituição de terras que consideram suas por direitos ancestrais".

Conforme a Figura 2, MAPUCHE RADICAL (grupo radical) é parte de MAPUCHE (comunidade indígena), o primeiro, por sua vez, é agente da REINVIDICAÇÃO do CHILE. CHILE é parte de MAPUCHE RADICAL, por que a comunidade já viveu no país e, por direitos ancestrais, atualmente o grupo radical considera que parte do Chile lhe pertence.

Nota-se que o grafo parte da perspectiva de que o MAPUCHE RADICAL é AMEAÇA e agente do ATENTADO, ou seja, o texto focaliza o ponto de vista do CHILE e compartilha a crença geral de que os grupos radicais que praticam 
o terrorismo são os "vilões". Logo, com base nos exemplos já analisados, observa-se que utilizar a semântica de frames para a análise textual é eficiente, pois é possível perceber as ideologias e sentidos acionados pelo texto.

$\mathrm{Na}$ figura 3, o grafo foi elaborado principalmente a partir dos seguintes trechos: "O governo português do primeiro-ministro António Costa, do Partido Socialista, no poder desde novembro de 2015, conseguiu reduzir o déficit fiscal ao mesmo tempo em que aumentou os salários e aposentadorias.". "O bom desempenho da economia coloca o país na posição de um 'oásis' em meio à turbulência política que atinge a Europa."

\section{Figura 3 - Representação em grafo do texto 3}

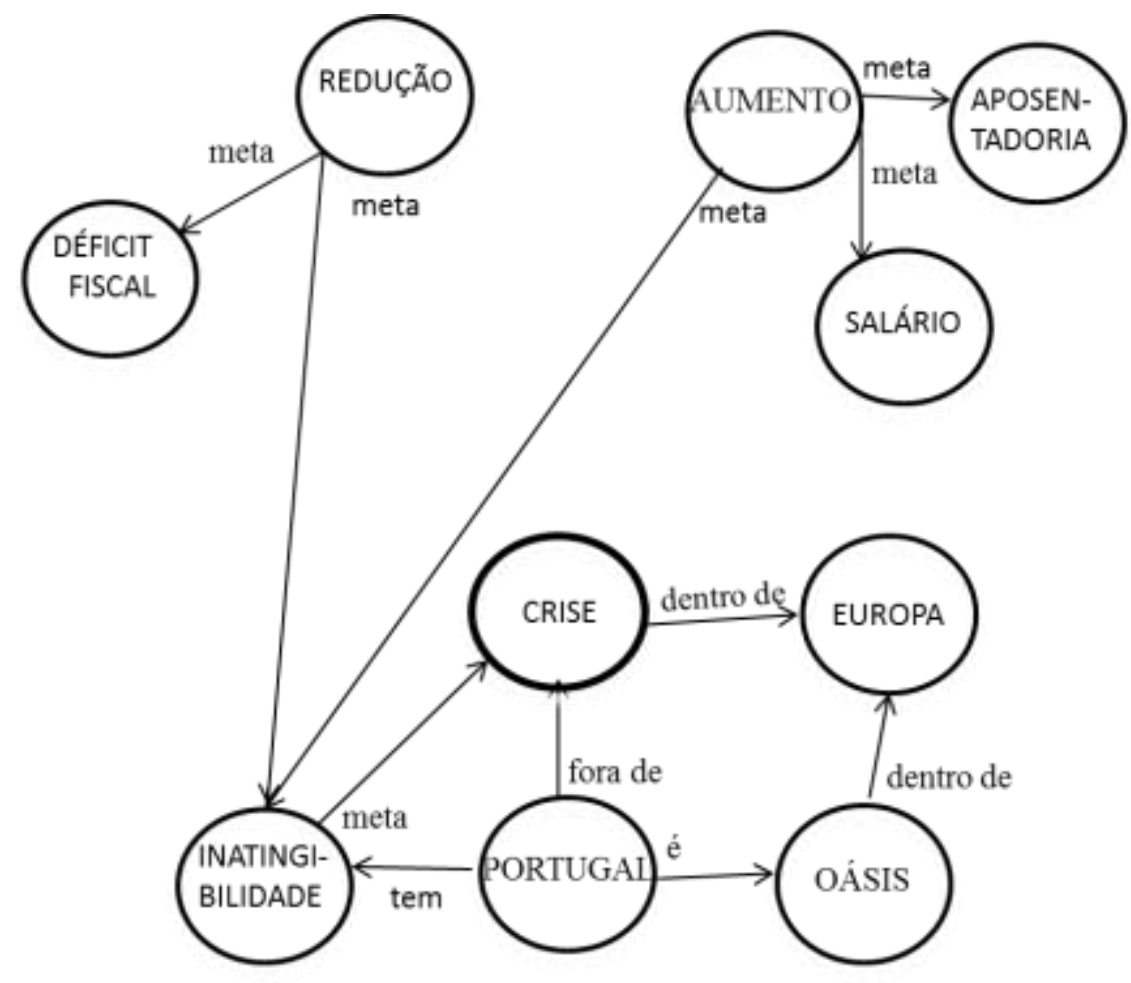

Fonte: Dados da pesquisa.

A estrutura desse grafo segue a mesma lógica das anteriores. PORTUGAL fora de CRISE significa que metaforicamente o país não está na crise. PORTUGAL tem INATINGIBILIDADE é uma relação PARTE-TODO de posse. REDUÇÃO tem como meta DÉFICIT FISCAL e AUMENTO tem como metas APOSENTADORIA e SALÁRIO. REDUÇÃO e AUMENTO (causas) têm como meta a INATINGIBILIDADE (consequência). Nesse caso, 
metaforicamente, a origem da TRAJETÓRIA é a causa e a meta é a consequência.

Um exemplo de metáfora complexa é observado neste texto, em PORTUGAL é OÁSIS dentro de EUROPA. O país não é atingido pela crise, da mesma forma que o oásis (região no deserto que possui água) não é atingido pela seca. Note que frames como DESERTO e OÁSIS não são adquiridos por intermédio de uma experiência subjetiva e perceptual do indivíduo, mas antes por um conceito construído culturalmente, o que configura a metáfora complexa.

Em relação às piadas analisadas, nas Figuras 4 e 5 , todas as falas foram colocadas na íntegra no grafo por remeter ao contrafactual. A fala 1 indica que ela aconteceu antes da fala 2. Como se trata de um diálogo, os agentes das falas recebem a seta indicando que são as metas, assim como de suas falas partem setas para o seu interlocutor.

A primeira piada analisada começa da seguinte forma: "dentro de uma cidade do interior, o rapaz da cidade encontra um senhor de uns 50 anos e lhe pergunta.... O diálogo então travado pode ser observado na Figura 4.

Figura 4 - Representação em grafo do texto 4

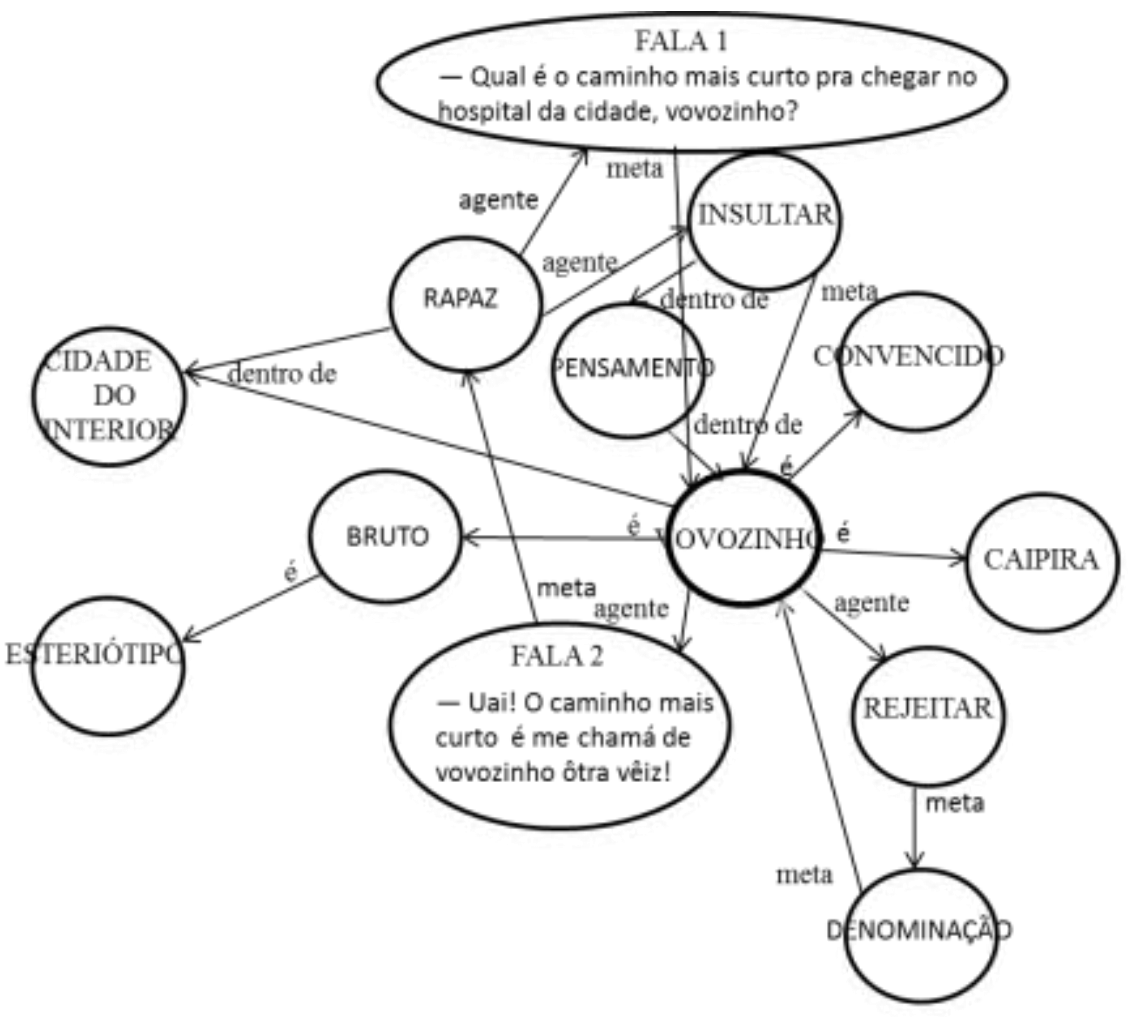

Fonte: Dados da pesquisa. 
Nesse exemplar, nota-se que o humor decorre do fato de o senhor se sentir insultado por ser chamado de vovozinho pelo rapaz. Note que RAPAZ insultar VOVOZINHO ocorre dentro do PENSAMENTO (espaço mental) do VOVOZINHO, porque foi assim que ele interpretou, causando, desse modo, o efeito humorístico.

Das 11 piadas analisadas, 3 continham algum tipo de estereótipo. Nesta piada, BRUTO é ESTEREÓTIPO, embora não esteja explícito, mas inferencialmente chega-se a essa conclusão pelo frame CIDADE DO INTERIOR. Uma vez sabido que em cidade do interior, especialmente em zonas rurais, os idosos são conhecidos por serem homens com temperamento hostil, no Brasil.

Figura 5 - Representação em grafo do texto 5

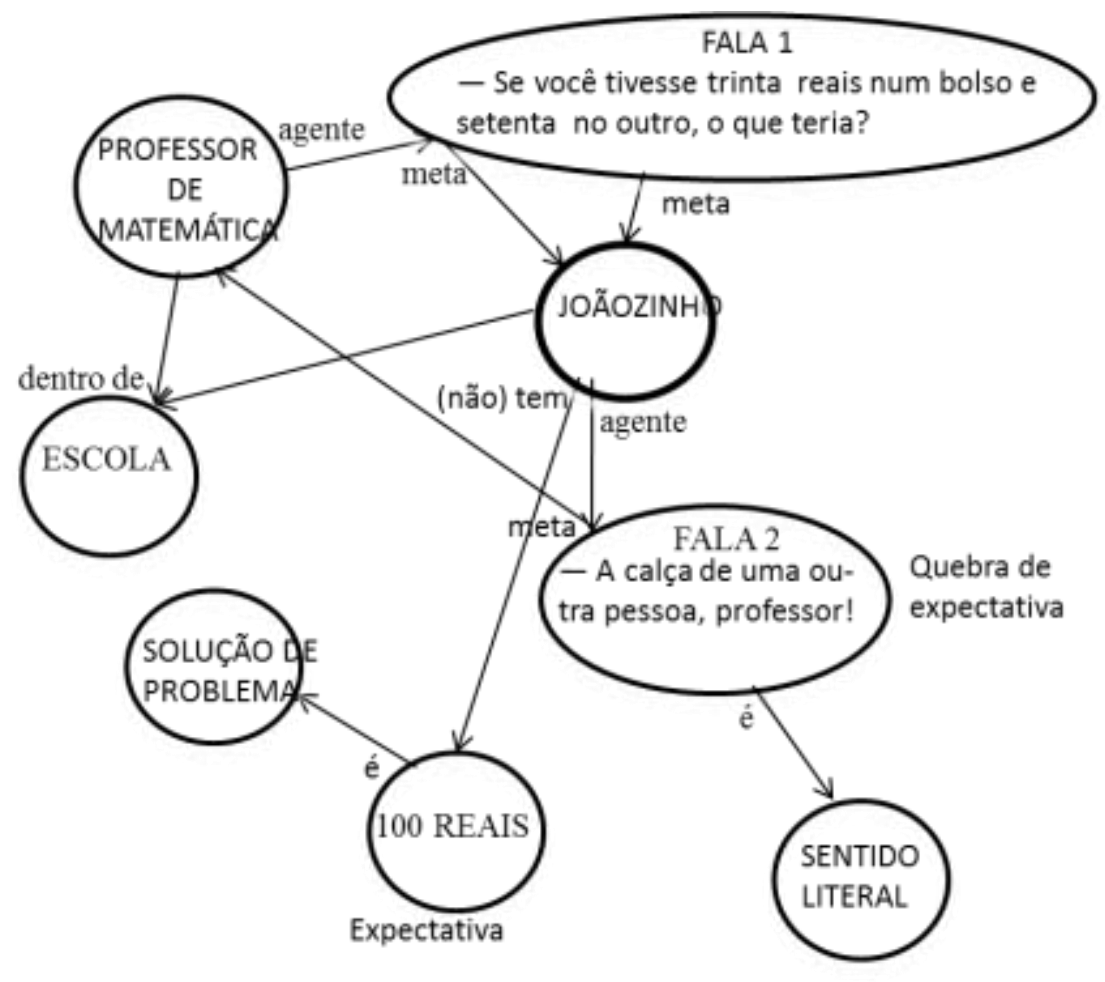

Fonte: Dados da pesquisa.

A semântica de frames também nos possibilita descrever com clareza as inferências do discurso. Por exemplo, na Figura 5, o PROFESSOR faz uma pergunta ao ALUNO, o que nos leva a concluir que ambos estão dentro de ESCOLA. Além disso, a inferência no humor é essencial, pois assim como na piada anterior, o humor é gerado pela quebra de expectativa, pois Joãozinho 
interpreta a pergunta do professor no sentido literal, revelado pela fala 2. A expectativa seria que sua resposta fosse "100 Reais", que é a solução do problema.

Deve-se salientar que a quebra de expectativa (FALA 2 é SENTIDO LITERAL) e expectativa (100 REAIS é SOLUÇÃO DE PROBLEMA) não são frames de sentido evocados pelo texto, mas sim frames interacionais, os quais orientam a nossa conduta e as nossas expectativas no discurso (DUQUE, 2015). Ou seja, eles estão em outro nível, que não o textual propriamente dito, mas situam-se mais próximos ao âmbito da inferência, isto é, mais próximos da interpretação do leitor;

O ideal era que não somente as inferências, mas também outras formas do contrafactual (futuro, passado, hipóteses, pensamento, representações), ou seja, tudo aquilo que foge dos sentidos acionados pelo contexto situacional do aqui e agora do texto fosse representado visualmente de maneira não linear junto com os outros frames, em virtude de esses frames e outros mecanismos cognitivos serem ativados em níveis diferentes de abstrações (FAUCONNIER, 2003; PEREIRA; CARDOSO, 2003; DIRVEN; FRANK; PÜTZ, 2003).

Para exemplificar com mais clareza, retomemos a Figura 3. Espaços mentais podem ser organizados por um frame mais específico, (por exemplo, RENAULT), ou em um frame hierarquicamente mais geral (MARCA), ou seja, em níveis cognitivos diferentes, assim como metáforas complexas (PORTUGAL É OÁSIS NO DESERTO) estão em um nível maior de abstração do que metáforas primárias (PORTUGAL fora de CRISE) e do que, como já deve ter ficado claro, construções literais.

Dessa forma, elaborar uma representação fiel de como o framing vai sendo ativado durante o discurso esbarra em barreiras intransponíveis até então, dado que ainda não há uma metodologia ou recursos eficientes para isso. Também se deve levar em conta que, nos grafos, os frames estão dispostos de uma forma na qual a ativação deles parece acontecer simultaneamente, o que obviamente não acontece, já que os mesmos são evocados no decorrer da leitura, processo que é mais perceptível em textos narrativos, em que há uma sequência de eventos. 


\section{Conclusão}

Este trabalho objetivou realizar uma análise do discurso por meio de uma abordagem baseada em frames. Por meio da análise de textos sobre terrorismo, preconceito, crise econômica e política e humor, elaboraram-se grafos dos principais frames ativados para a compreensão global dos textos.

Nossa análise traz importantes contribuições à Linguística Cognitiva, especificamente à Semântica de frames, uma vez que essa área ainda carece de estudos mais aprofundados, especialmente no que concerne à metodologia analítica. Esta pesquisa propôs um modelo de análise em que os frames estão conectados por relações e papéis dos esquemas imagéticos, algo que até então não havia sido feito.

Portanto, o uso dos esquemas-I para a conexão dos nós mostrou ser eficiente, uma vez que, como pode ser observado na análise, foi possível representar adequadamente a relação e a articulação dos conceitos na formação de frames complexos por meio da constituência, de tal maneira que, com efeito, pudemos observar que são os esquemas imagéticos e seus desdobramentos sobre as metáforas primárias que estruturam nossa cognição, ressaltando-se, desse modo, a importância da mente corporificada na construção dos frames (LAKOFF, 1980; SANTOS, 2011).

A abordagem de análise do discurso adotada neste trabalho possibilitou uma melhor compreensão da construção de sentido nas notícias e piadas analisadas, uma vez que, adotando-se a identificação de frames como ferramenta analítica, pudemos verificar com mais riqueza de detalhes como a linguagem atua na ativação e estruturação de mecanismos cognitivos como frames, esquemas, espaços mentais e metáforas.

Concluímos que a elaboração dos grafos foi um meio eficiente para a representação dos conceitos evocados pelo texto. Outrossim, por meio dos grafos, verificamos como visões de mundo são construídas e perspectivadas visando à persuasão de comportamentos sociais e políticos.

Vale salientar que essa área requer um maior aprofundamento para o aprimoramento metodológico da identificação de frames e elaboração dos grafos, já que, neste trabalho, ficou explícito que a representação dos conceitos 
em redes articuladas mostra-se uma alternativa bastante limitada, dessarte, representando de forma precária como realmente os frames são ativados durante a leitura.

\section{Referências}

ARAÚJO, J. D. C. O processo cognitivo-discursivo de construção de sentido em narrativas: uma abordagem baseada em frames em $O$ pequeno príncipe. 140f. Dissertação (Mestrado em Estudos da Linguagem) - Centro de Ciências Humanas, Letras e Artes, Universidade Federal do Rio Grande do Norte, Natal, 2017.

BERTOLDI, A.; CHISHMAN, R. L. O. Aplicando a Semântica de Frames na descrição do Direito brasileiro. Veredas, Juiz de Fora, v. 17, p. 117-133, 2013.

BOUVERET, M.; SWEETSER, E. Multi-frame semantics, metaphoric extensions, and grammar. In: KWON, I.; PRITCHETTE, H.; SPENCE, J. (org.). Thirty-Fifth Annual Meeting of the Berkeley Linguistics Society (BLS). Berkeley: Berkeley Linguistics Society, p. 49-59, 2009.

CROFT, W.; CRUSE, D. A. Cognitive linguistics. New York: Cambridge University Press, 2004.

DIRVEN, R.; FRANK, R.; PÜTZ, M. Cognitive models in language and thought: ideology, metaphors, and meanings. Berlin: De Gruyter, 2003.

DUQUE, P. H. Discurso e cognição: uma abordagem baseada em frames. Revista da ANPOLL, v. 1, n. 39, p. 25-48, 2015.

DUQUE, P. H.; COSTA. M. A. A análise construcional do discurso: uma alternativa cognitiva para o estudo dos gêneros discursivos. In: SIMPÓSIO INTERNACIONAL DE ESTUDOS DE GÉNEROS TEXTUAIS, 6., 2011, Natal. Anais... Natal, 2011.

FAUCONNIER, G. Mental spaces: aspects of meaning construction in natural language. Cambridge: Cambridge University Press, [1985] 1994.

FAUCONNIER, G. Mappings in thought and language. New York, NY, US: Cambridge University Press, 1997.

FAUCONNIER, G. Mental spaces, language modalities, and conceptual integration. In: TOMASELLO, M.; ERLBAUM, L. (org.). The New Psychology of Language: cognitive and functional approaches to Language Structure (I). New York: Psychology Press, 2014. p. 230-258. 
FAUCONNIER, G.; TURNER, M. Conceptual blending, form and meaning. Recherches en communication: sémiotic cognitive. v. 19, n. 19, p. 57-86, 2003.

FAUCONNIER, G.; TURNER, M. Conceptual projection and middle spaces. Report 9401. San Diego: University of California, 1994.

FAUCONNIER, G.; TURNER, M. Conceptual integration networks. Cognitive Science, v. 22, n. 2, p. 133-187, 1998.

FAUCONNIER, G.; TURNER, M. The way we think: conceptual blending and the mind's hidden complexities. New York: Basic Books, 2002.

FELDMAN, J. A. From molecules to metaphors: a neural theory of language. Cambridge, Ma: Bradford; MIT Press, 2006.

FILLMORE, C. J. An alternative to checklist theories of meaning. In: COGEN, C. et al (org.). Proceedings of the First Annual Meeting of the Berkeley Linguistics Society. Berkeley: Berkeley Linguistics Society, p. 123-131, 1975.

FILLMORE, C. J. Frame semantics and the nature of language. In: HARNARD, S. R.; STEKLIS, H. D.; LANCASTER, J. (org.). Origins and evolution of language and speech. Nova York: New York Academy of Sciences, 1976.

FILLMORE, C. J. Scenes-and-frames semantics, linguistic structures processing. In: ZAMPOLLI, A. (org.). Fundamental studies in computer science. Amsterdan: North Holland Publishing, 1977. p. 55-88.

FILLMORE, C. J. Frame Semantics. In: LINGUISTICS SOCIETY OF KOREA (org.). Linguistics in the morning calm. Seoul: Hanshin, p. 111-138, p. 1982.

FILLMORE, C. J. Frames and the semantics of understanding. Quaderni di Semantica, v. 5, n. 2, p. 222-254, p. 1985.

FERRARI, L. V. Reportar condicionais: uma questão de ponto de vista. Revista de Estudos da Linguagem, v. 16, p. 117-140, 2008.

GIBBS, R. W. Why Cognitive Linguistics should care more about empirical methods. In: GONZALEZ-MARQUEZ, M.; MIDDELBURG, I.; COULSON, S.; SPIVEY, M. (org.). Methods in Cognitive Linguistics. Amsterdam: John Benjamins, 2007.

GRADY, J. E. Foundations of meaning: primary metaphors and primary scenes. PhD Dissertation, University of California, Berkeley, 1997.

JOHNSON, M. The body in the mind: the bodily basis of meaning, imagination, and reason. Chicago: University of Chicago Press, 1987.

LAKOFF, G. Women, fire, and dangerous things. Chicago: University of Chicago Press, 1987. 
LAKOFF, G. The invariance hypothesis: Is abstract reason based on imageschemas? Cognitive Linguistics, Edmonton, v. 1, n. 1, p. 39-74, 1990.

LAKOFF, G. The contemporary theory of metaphor. In: ORTONY, A. (org.). Metaphor and thought. 2. ed. New York: Cambridge University Press, 1993. p. 202-251.

LAKOFF, G. Don't think of an elephant!: know your values and frame the debate. The essential guide for progressives, including post-election updates. Chelsea, VT: Chelsea Green Publishing Company, 2004.

LAKOFF, G.; JOHNSON, M. Metaphors we live by. Chicago: University of Chicago Press, 1980.

LANGACKER, R. W. Cognitive Grammar: a basic introduction. New York: Oxford University Press, 2008.

MARCUSCHI, L. A. Gêneros textuais: definição e funcionalidade. In: DIONÍSIO, A. et al. Gêneros textuais e ensino. Rio de Janeiro: Lucerna, 2002.

MOK, E.; BRYANT, J.; FELDMAN, J. Scaling up to mental spaces: proceedings of the Second International Workshop on Scalable Natural Language Understanding, Boston, 2004.

MOREIRA, A.; SALOMÃO, M. M. M. Análise ontológica aplicada ao desenvolvimento de frames. Alfa: Revista de Linguística, São José do Rio Preto, v. 56, n. 2, p. 491-521, 2012.

MIRANDA, N. S.; LOURES, L. F. Da análise semântica do discurso à ação educativa: um mapa da crise da sala de aula. Ling. (dis)curso, Tubarão, v. 16, n. 3, p. 525-546, 2016. Disponível em: http://www.scielo.br/scielo.php?script=sci_arttext\&pid=S1518$76322016000300525 \&$ Ing=en\&nrm=iso. Acesso em: 08 maio 2018.

PEREIRA, F. C.; CARDOSO, A. Optimality principles for Conceptual Blending: a first computational approach. The Interdisciplinary Journal of Artificial Intelligence and the Simulation of Behaviour (AISB Journal), Organização: E. Alonso; G. Wiggins, v. 1, n. 4, SSAISB, 2003.

PETRUCK, M. R. L. Frame Semantics. In: VERSCHUEREM, J. et. al (org.). Handbook of pragmatics. Philadelphia: John Benjamins, 1996.

SANTOS, R. Y. O esquema imagético LIGAÇÃO como elemento básico na construção da metáfora. Cadernos do IL, n. 46, p. 25-44, 2011.

SULLIVAN, K. S. Grammar in metaphor: a construction grammar account of metaphoric language. Doctoral dissertation, University of California, Berkeley, 2007.

SMITH, M. B. Cataphoric pronouns as mental space designator; Their conceptual import and discourse function. In: CONTINI-MORAYA, E., 
KIRSNER, R. S.; RODRIGUEZ-BACHILLER, B. (org.). Cognitive and communicative approaches to linguistic analysis. John Benjamins Publishing, 2004. p. 61-90. (Studies in Functional and Structural Linguistics, 51)

TEIXEIRA, A. P. A semântica de frames na análise do discurso docente: indicadores de sucesso das práticas de ensino de Língua Portuguesa. 2014. 161 f. Dissertação (Mestrado em Linguística) - Programa de Pós-graduação em Linguística, Universidade Federal de Juiz de Fora, Juiz de Fora, 2014. 